\title{
Research on cold start and new data evaluation method influence on RDE test for light-duty vehicles
}

\author{
Feng Yan*, Nan Xie, Yuwei Wang, and Jingyuan Li \\ China Automotive Technology and Research Center Co., Ltd., Tianjin 300300
}

Keywords: real driving emission, cold start, chassis dynamometer, propose.

\begin{abstract}
The Real Driving Emission test (RDE) required in China 6 regulation (GB 18352.6-2016) followed the EU 6 regulation (EC 2016/646), where cold start is excluded in emission calculation. Since cold start is an important stage of pollutant formation, the European Union had developed further requirements for cold start in EU 6 regulation (EC 2017/1154 and EC 2018/1832), which created generation gaps between China 6 and EU 6 RDE test requirements. This work is based on real RDE tests on public road and repetition tests on Chassis dynamometer with relevant cold start requirements of EC 2017/1154 described and demonstrated, the data evaluation method difference between China 6 regulation including cold start and new requirements in EC 2018/1832 are compared, and the following cold start requirements of China 6 RDE regulation is discussed and proposed.
\end{abstract}

\section{Introduction}

The Limits and measurement methods for emissions from light-duty vehicles (CHINA 6) [1] is issued on December 23, 2016 (known as GB 18352.6-2016, and CN 6 for short), in which Real Driving Emission test (RDE) is introduced as type II test by referring to the first two RDE packages of EU regulation (EC 2016/427 [2] and EC 2016/646 [3]) with some requirements of OVC-HEV mainly referred to the third package (EC 2017/1154 [4]). Since the publication of $\mathrm{CN} 6$ regulation, the European Union had further updated their RDE requirements in EC 2017/1154 known as the third package and EC 2018/1832 [5] known as the fourth package in 2017 and 2018 respectively. The continuous updating of EU requirements has put forward more comprehensive requirements for RDE, adding the cold start requirements, hybrid vehicle test procedures, PN emission methods, in-use compliance requirements, and etc. In the fourth package, the data evaluating method is modified based on raw emission and the ratio of $\mathrm{CO} 2$ emission between RDE and WLTC test, and the MAW method and Power Binning method used throughout the first three packages are discarded. Continuous updating of EU standards had caused generation gaps between China 6 and EU 6 RDE requirements. Taking the third package as an example, the

\footnotetext{
*Corresponding author: yanfeng2015@catarc.ac.cn
} 
differences between CN 6 (GB 18352.6-2016) and EU 6 (EC 2017/1154) can be roughly divided into two categories. The first category is the consciously changes due to the actual environmental and traffic situation of China, including the further expansion of altitude requirement, limitation of the maximum vehicle speed, and etc. The second category is the difference caused by generation gaps, including the requirement of cold start, vehicle preconditioning and soaking, etc. The main differences between $\mathrm{CN} 6$ and EU $6 \mathrm{RDE}$ requirements are specified in Table 1.

Table 1. RDE requirement differences between GB 18352.6-2016 and EC 2017/1154.

\begin{tabular}{|c|c|c|}
\hline Contents & CN 6 (GB 18352.6-2016) & EU 6 (EC 2017/1154) \\
\hline Altitude requirement $\mid \begin{array}{l}\mathrm{F} \\
\mathrm{c} \\
2\end{array}$ & $\begin{array}{l}\text { Further extended to } 2400 \mathrm{~m} \text { (the } \\
\text { correction factor between } 1300 \text { and } \\
2400 \text { is set to } 1.8 \text { ) }\end{array}$ & Only Extended to $1300 \mathrm{~m}$ \\
\hline Data evaluation & MAW & MAW, Power Binning \\
\hline $\begin{array}{lr}\begin{array}{l}\text { Primary } \\
(\mathrm{CO} 2\end{array} & \text { tolerance } \\
\text { curve }) & \text { characteristic }\end{array} \mid \mathrm{b}$ & $\begin{array}{l}\text { tol1 for normality verification can } \\
\text { be increased to } \pm 50 \%\end{array}$ & $\begin{array}{l}\text { The upper tolerance tol1 shall never } \\
\text { exceed }+30 \%\end{array}$ \\
\hline $\begin{array}{l}\text { Cold start/Cold start } \\
\text { data }\end{array}$ & Not required/Excluded & Required/Included \\
\hline Preconditioning & Not required & At least $30 \mathrm{~min}$ \\
\hline Soaking & Not required & Between 6-56 hours \\
\hline Soaking environment & Not required & $\begin{array}{l}\text { No specific requirement, but if the } \\
\text { vehicle was conditioned for the last three } \\
\text { hours prior to the test at an average } \\
\text { temperature that falls within the } \\
\text { extended range, then the correction } \\
\text { factor shall apply to the data collected } \\
\text { during the cold start period, even if the } \\
\text { running conditions are not within the } \\
\text { extended temperature range. }\end{array}$ \\
\hline Maximum speed & $120 \mathrm{~km} / \mathrm{h}$ & $145 \mathrm{~km} / \mathrm{h}$ \\
\hline Mileage & Any mileage & $>3000 \mathrm{~km}$ \\
\hline $\mathrm{NOX}(\mathrm{CF})$ & \multirow[t]{2}{*}{ 2.1(will be evaluated by 2022.7.1) } & $\begin{array}{l}2.1(2017.9 .1-2020.1 .1) \\
1.0+\text { margin }=1.43(2020.1 .1-) \\
\end{array}$ \\
\hline $\mathrm{PN}(\mathrm{CF})$ & & $1.0+$ margin $=1.5(2017.9 .1-)$ \\
\hline Extensions & $\begin{array}{l}\text { Extensions are the same as Type I } \\
\text { test }\end{array}$ & PEMS family \\
\hline $\begin{array}{l}\text { Hot start test for } \\
\text { type-approval }\end{array}$ & Not required & Required \\
\hline type-approval done by $f$ & All by technical service & $50 \%$ test can be self-done by the OEM \\
\hline $\begin{array}{l}\text { Average speed during } \\
\text { cold start }\end{array}$ & Not required & $15-40 \mathrm{~km} / \mathrm{h}$ \\
\hline $\begin{array}{l}\text { Maximum speed } \\
\text { during cold start }\end{array}$ & Not required & Less than $60 \mathrm{~km} / \mathrm{h}$ \\
\hline Idle time after ignition $\mathrm{I}$ & Not required & Less than $15 \mathrm{~s}$ \\
\hline $\begin{array}{l}\text { Stop time during cold } \\
\text { start }\end{array}$ & Not required & Less than 90s \\
\hline $\begin{array}{ll}\text { Data } \\
\text { direction }\end{array}$ & Forward of Backward & Forward \\
\hline
\end{tabular}

In the fourth package of EU regulation (EC 2018/1832), additional requirements of $\mathrm{RDE}$ tests are released, $\mathrm{CO} 2$ window requirements between ICE vehicles, NOVC-HEVs and OVC-HEVs were unified and a new data evaluation method is introduced based on raw 
emission and the ratio of $\mathrm{CO} 2$ emission between RDE and WLTC, meanwhile the MAW method and Power Binning method used throughout the first three packages are discarded.

For ICE vehicles, NOVC-HEVs and OVC-HEVs, the new data evaluation method can be expressed as:

$$
\mathrm{M}_{\mathrm{RDE}, \mathrm{k}}=\mathrm{m}_{\mathrm{RDE}, \mathrm{k}} \cdot \mathrm{RF}_{\mathrm{k}}
$$

Where $M_{R D E, k}$ is the final RDE distance-specific mass of gaseous pollutants or particle pollutants $(\mathrm{mg} / \mathrm{km}, \# / \mathrm{km})$.

$\mathrm{m}_{\mathrm{RDE}, \mathrm{k}}$ is the distance-specific mass of gaseous pollutant $[\mathrm{mg} / \mathrm{km}]$ or particle number $[\# / \mathrm{km}]$ emissions, emitted over the complete RDE trip and prior to any correction.

$\mathrm{k}$ can represent either urban or total trip.

$\mathrm{RF}_{\mathrm{k}}$ is the result evaluation factor, which can be calculated by $\mathrm{RF}_{\mathrm{L} 1}, \mathrm{RF}_{\mathrm{L} 2}$ and the ratio between the $\mathrm{CO} 2$ emissions measured during RDE and WLTC $\left(\mathrm{r}_{\mathrm{k}}\right)$. Upon the request of the manufacturer and only for type approvals granted before 1 January $2020, \mathrm{RF}_{\mathrm{L} 1}$ is 1.20 and $\mathrm{RF}_{\mathrm{L} 2}$ is 1.25 , and in all other cases $\mathrm{RF}_{\mathrm{L} 1}$ is 1.30 and $\mathrm{RF}_{\mathrm{L} 2}$ is 1.50 .

For ICE vehicles and NOVC-HEVs, $r_{k}$ can be expressed as:

$$
\mathrm{r}_{\mathrm{k}}=\frac{\mathrm{M}_{\mathrm{CO}_{2}, \mathrm{RDE}, \mathrm{k}}}{\mathrm{M}_{\mathrm{CO}_{2}, \mathrm{WLTP}, \mathrm{k}}}
$$

Where $\mathrm{M}_{\mathrm{CO}_{2}, \mathrm{RDE}, \mathrm{k}}$ is the CO2 emissions measured during RDE test, $\mathrm{M}_{\mathrm{CO}_{2}, \mathrm{WLTP}, \mathrm{k}}$ is the $\mathrm{CO} 2$ emissions measured during WLTC test.

For OVC-HEVs, $r_{k}$ can be expressed as:

$$
\mathrm{r}_{\mathrm{k}}=\frac{\mathrm{M}_{\mathrm{CO}_{2}, \mathrm{RDE}, \mathrm{k}}}{\mathrm{M}_{\mathrm{CO}_{2}, \mathrm{WLTP}, \mathrm{k}-\mathrm{CS}, \mathrm{t}}} \cdot \frac{0,85}{\mathrm{IC}_{\mathrm{k}}}
$$

Where $\mathrm{IC}_{\mathrm{k}}$ is the ratio of the distance driven either in urban or total trip with the combustion engine on divided by the total urban or total trip distance:

$$
\mathrm{IC}_{\mathrm{k}}=\frac{\mathrm{d}_{\mathrm{ICE}, \mathrm{k}}}{\mathrm{d}_{\mathrm{ICE}, \mathrm{k}}+\mathrm{d}_{\mathrm{EV}, \mathrm{k}}}
$$

Once $r_{k}$ has been laid down, the result evaluation factor $\mathrm{RF}_{\mathrm{k}}$ can be calculated following Table 2 .

Table 2. The result evaluation factors calculation.

\begin{tabular}{c|c|c}
\hline When: & Then the result evaluation factor $\mathrm{RF}_{\mathrm{k}}$ is: & Where: \\
\hline $\mathrm{r}_{\mathrm{k}} \leq \mathrm{RF}_{\mathrm{L} 1}$ & $\mathrm{RF}_{\mathrm{k}}=1$ & \\
\hline $\mathrm{RF}_{\mathrm{L} 1}<\mathrm{r}_{\mathrm{k}} \leq \mathrm{RF}_{\mathrm{L} 2}$ & $\mathrm{RF}_{\mathrm{k}}=\mathrm{a}_{1} \mathrm{r}_{\mathrm{k}}+\mathrm{b}_{1}$ & $\mathrm{a}_{1}=\frac{\mathrm{RF}_{\mathrm{L} 2}-1}{\begin{array}{c}{\left[\mathrm{RF}_{\mathrm{L} 2}\left(\mathrm{RF}_{\mathrm{L} 1}-\mathrm{RF}_{\mathrm{L} 2}\right)\right]} \\
\mathrm{b}_{1}=1-\mathrm{a}_{1} \mathrm{RF}_{\mathrm{L} 1}\end{array}}$ \\
\hline $\mathrm{r}_{\mathrm{k}}>\mathrm{R}_{\mathrm{FL} 2}$ & $\mathrm{RF}_{\mathrm{k}}=\frac{1}{\mathrm{r}_{\mathrm{k}}}$ & \\
\hline
\end{tabular}

To minimize the influence of public traffic to RDE results and for the purpose of modifying the following RDE requirements of China 6 regulation, RDE tests on public road and repetition tests on Chassis dynamometer were carried out, and the relevant cold start requirements and new data evaluation method in EU 6 regulation were compared, discussed and proposed.

\section{Results and discussion}

\subsection{The influence of cold start on RDE}


Cold start for the purposes of RDE is the period from the test start until the point when the vehicle has run for 5 minutes, or if the coolant temperature is determined, it ends once the coolant is at least $70{ }^{\circ} \mathrm{C}$ for the first time but no later than 5 minutes after test start. Even though the emission during cold start is excluded in the current CN 6 RDE regulation, but in fact, cold start is an important contributor to emissions from light passenger and commercial vehicles, being especially important in urban areas where most of the cold starts occur. Especially during winter, cold starts contribute significantly to the air pollution in cities and should therefore be regulated appropriately. Figure 1 shows the emission ratio between cold start and total trip during 5 individual RDE tests, it can be seen that the cold start accounts for a considerable proportion of emission during RDE tests, the NOx and PN emission during cold start accounts for $4 \% \sim 12 \%$ and $2 \% \sim 11 \%$ of the total RDE emission respectively.

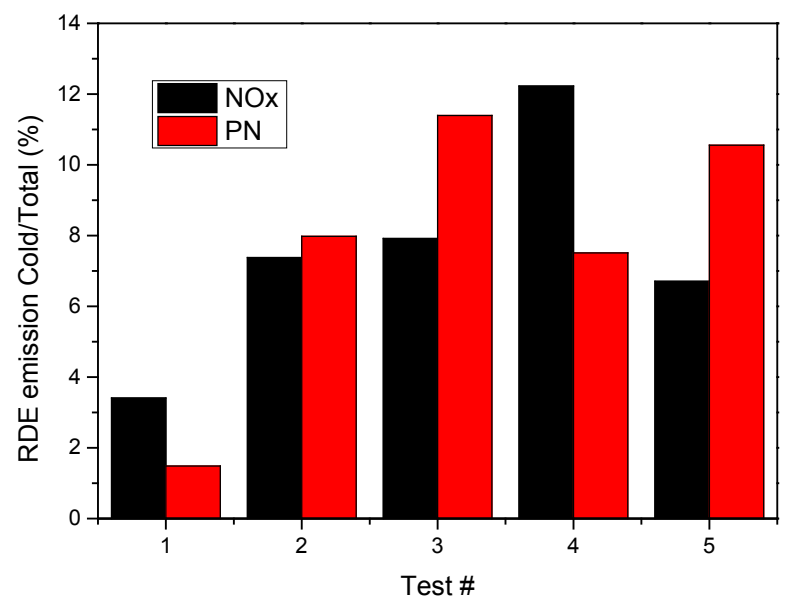

Fig. 1. Emission ratio between cold start and total trip.

The European Union had put forward clear requirements for cold start at the beginning of formulating the third RDE package. By considering the demands of stakeholders, two alternatives were provided: (1) do not make major changes to the second package, only add relevant requirements of cold start; (2) evaluate the emissions of cold start and hot start separately, add weighting coefficient to determine the final emission. These two alternatives are still valuable if we want to further improve and add cold start requirements for $\mathrm{CN} 6 \mathrm{RDE}$ regulation.

The first alternative can better integrate with the existing $\mathrm{CN} 6$ regulation without fundamental changes, but some problems may spotlight if no corresponding requirements are added:

1) The Moving Average Window (MAW) in CN 6 used for RDE calculation divided the test results into a series of data subsets, which has a shortage that the data at the beginning and at the end of test are contained in less data subsets than the data at the middle of the test, leading to less weighting in the emission statistics of the data during cold start, or on the other hand, underestimate this high emissions stage.

2) The data can be calculated either forward or backward, and the MAW has a risk that the data during cold start stage are contained in less data subsets if the data is calculated backward than forward, in some extreme cases, the data during cold start may not be included in any subsets;

3) In MAW, if the window falls outside the primary tolerance, its weight will be reduced from 1, which may lead to a test loophole - the subset of data including cold start can be excluded from the normal window range by extreme driving behavior to avoid the 
statistics of the high pollutant emission during cold start.

From the above discussion, we can conjecture an obvious risk that simply including cold start into the existing data evaluation without proper supplement may not be able to reflect the important role of cold start in vehicle emissions.

In theory, the second alternative can better represent the emission state of cold start in actual vehicle usage, but some realistic problems still exist:

1) Due to the lack of mature foreign experience, reasonable weights need lots of data to evaluate, which is not yet available or sufficient at present stage;

2) It changes the original $\mathrm{CN} 6$ regulations fundamentally, which is not suitable right now for the $\mathrm{CN} 6$ regulation is not yet implemented nationwide, and it will increase the complexity of RDE supervision.

After the final balance of advantages and disadvantages, the European Union had chosen the first alternative but supplemented the regulation properly to better measure the role of cold start in pollutant emissions including: 1) The calculation shall be run from the first point (forward); 2) Before RDE testing, the vehicle shall be preconditioned by driving for at least $30 \mathrm{~min}$, parked with doors and bonnet closed and kept in engine-off status within moderate or extended altitude and temperatures between 6 and 56 hours; 3) If the vehicle was conditioned for the last three hours prior to the test at an average temperature that falls within the extended range, then the data collected during the cold start period shall be divided by a value of 1.6 , even if the running conditions are not within the extended temperature range; 4) The average speed (including stops) during cold start period shall be between 15 and $40 \mathrm{~km} / \mathrm{h}$, the maximum speed during the cold start period shall not exceed $60 \mathrm{~km} / \mathrm{h} ; 5)$ The idling immediately after the first ignition of the combustion engine shall be kept to the minimum possible and it shall not exceed $15 \mathrm{~s}$, the vehicle stop during the entire cold start period shall be kept to the minimum possible and it shall not exceed $90 \mathrm{~s} ; 6$ ) For all averaging windows including cold start data points, the weighting function is set to 1 ; and etc.

For the further developments of $\mathrm{CN} 6 \mathrm{RDE}$ regulation, cold start requirements should also follow the principle of supplementing rather than fundamental changing of current regulation, but still can evaluate the emission level of cold start more effectively. From this point of view, it is more reasonable and feasible to refer to the experience of EU 6 regulation by introducing part of the requirements of the third package. But due to the differences in traffic and environment between European and China, it is necessary to verify the rationality of these new requirements, and evaluate the influences to the current regulation system.

\subsection{Calculation direction}

In current regulation, RDE data can be calculated either from the first point (forward) or from the last point (backward), but as mentioned earlier, the MAW has a risk that the data during cold start stage are contained in less data subsets if the data is calculated backward than forward, in some extreme cases, the data during cold start may not be included in any subsets. Figure 2 shows the influence of cold start and data processing direction on the urban window number. It can be seen from Figure 2 that when cold start is added, the number of urban windows increases significantly, and the newly added windows including cold start emission would affect the final urban and total result. However, according to the current data segmentation rules, the data in the cold start phase will be included in fewer windows if calculated backward rather than forward. As shown in Figure 2, the number of urban windows will be reduced by $20 \%-37 \%$ if calculation direction changed from forward to backward. This will further affect the proportion of cold start in the urban stage, which is not conducive to the reasonable performance of the important role of cold start in 
emission statistics. Therefore, it is suggested that the revision of $\mathrm{CN} 6$ should refer to the revision principle of the EU standard by forcing the data processing direction forward.

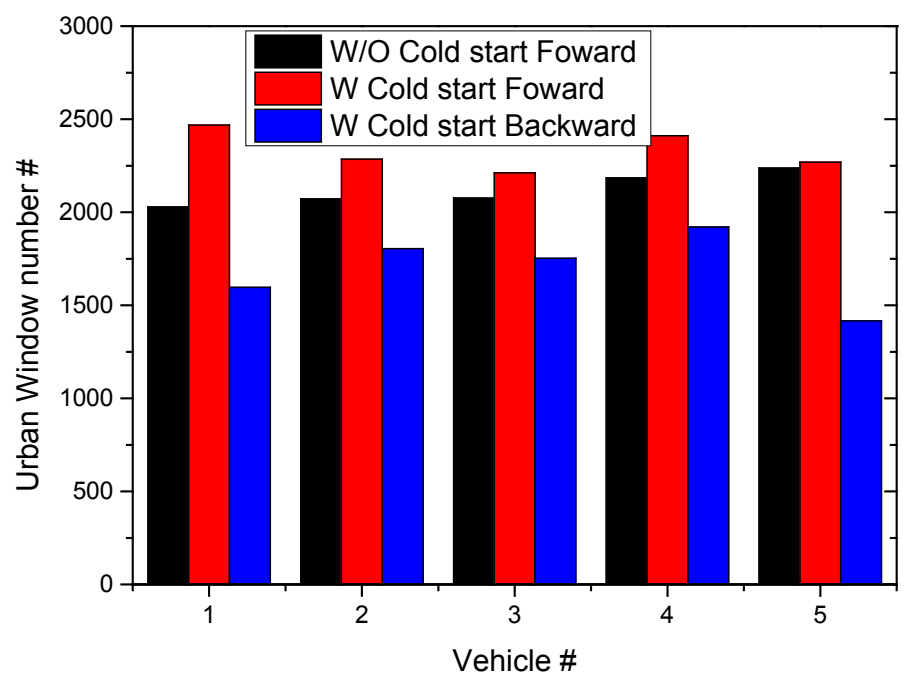

Fig. 2. The influence of cold start and data processing direction on the urban window number.

\subsection{Preconditioning and soaking influence}

In order to evaluate the impact of different preconditioning and soaking methods on the RDE results, especially the emissions in the cold start stage, and to minimize the impact of the external traffic environment, the same RDE velocity curve was repeated on Chassis dynamometer during a series of tests by the same driver to simulate the real driving condition on public road but without public traffic influence, the vehicle status is shown in Figure 3.
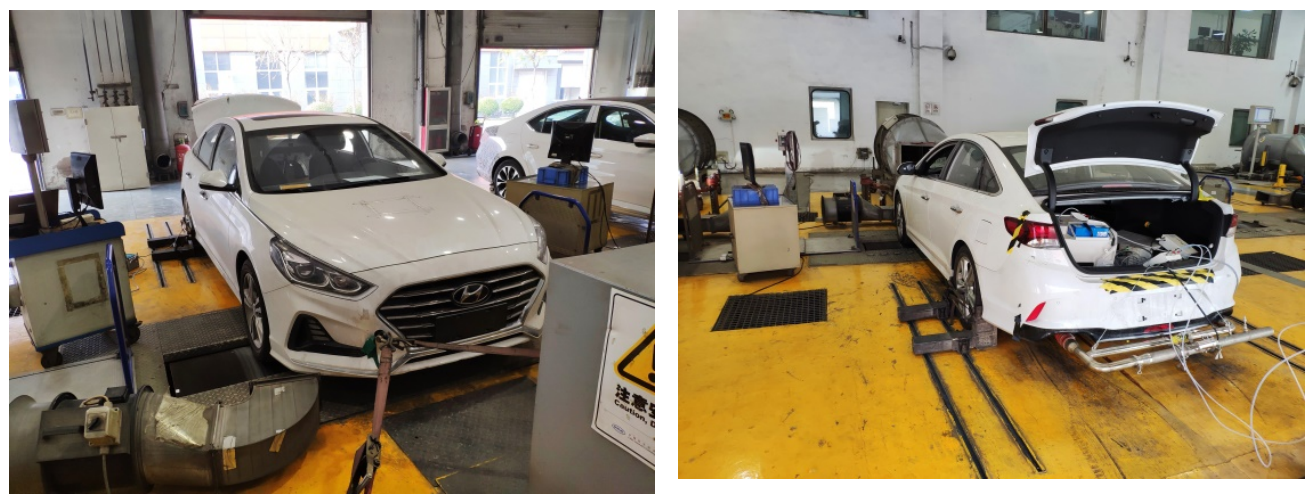

Fig. 3. Repetition RDE tests on Chassis dynamometer.

From Table 1, we have known that the requirements of preconditioning and soaking in the third package of EU regulation is very general, which actually takes into account the diversity of actual use of vehicles. Our research will demonstrate the impact of such wide requirements on vehicle $\mathrm{RDE}$ emissions by testing vehicle at different preconditioning and soaking situations. The overall repetition test arrangement is shown in Table 3. 
Table 3. Repetition RDE test schedule.

\begin{tabular}{|c|c|c|c|c|c|c|c|c|}
\hline & Day 1 & Day 2 & Day 3 & Day 4 & Day 5 & Day 6 & Day 7 & Day 8 \\
\hline $\begin{array}{l}\text { A } \\
\text { M }\end{array}$ & \multirow[b]{2}{*}{$\begin{array}{l}\text { Vehicle } \\
\text { and } \\
\text { PEMS } \\
\text { equipme } \\
\text { nt check }\end{array}$} & & $\begin{array}{l}\text { Repetition } \\
\text { RDE tests } \\
\text { on Chassis } \\
\text { dynamomet } \\
\text { er }\end{array}$ & $\begin{array}{l}\text { Repetition } \\
\text { RDE tests } \\
\text { on Chassis } \\
\text { dynamomet } \\
\text { er }\end{array}$ & $\begin{array}{l}\text { Repetiti } \\
\text { on RDE } \\
\text { tests on } \\
\text { Chassis } \\
\text { dynamo } \\
\text { meter }\end{array}$ & \multirow[b]{2}{*}{$\begin{array}{l}\text { Soaking } \\
\text { outside }\end{array}$} & \multirow[b]{2}{*}{$\begin{array}{l}\text { Soaking } \\
\text { outside }\end{array}$} & $\begin{array}{l}\text { Soaking } \\
\text { outside }\end{array}$ \\
\hline $\begin{array}{l}P \\
M\end{array}$ & & $\begin{array}{l}\text { Repetition } \\
\text { RDE tests on } \\
\text { Chassis } \\
\text { dynamometer } \\
\text { (No } \\
\text { preconditioni } \\
\text { ng and } \\
\text { soaking, cold } \\
\text { start) }\end{array}$ & $\begin{array}{l}\text { Preconditio } \\
\text { n vehicle at } \\
\text { constant } \\
\text { speed of } 30 \text {, } \\
70,90 \mathrm{~km} / \mathrm{h} \\
\text { with each } \\
\text { speed for } \\
10 \text { minutes }\end{array}$ & $\begin{array}{l}\text { Preconditio } \\
\mathrm{n} \text { vehicle at } \\
\text { WLTC } \\
\text { cycle }\end{array}$ & $\begin{array}{l}\text { Precondi } \\
\text { tion } \\
\text { vehicle } \\
\text { at } \\
\text { WLTC } \\
\text { cycle }\end{array}$ & & & $\begin{array}{l}\text { Repetitio } \\
\mathrm{n} \text { RDE } \\
\text { tests on } \\
\text { Chassis } \\
\text { dynamo } \\
\text { meter }\end{array}$ \\
\hline
\end{tabular}

In order to ensure the test accuracy, the PEMs validation test was completed before the whole series of repetition test, the comparison results are shown in Table 4.

Table 4. PEMS validation test results.

\begin{tabular}{l|l|l|l}
\hline pollutant & $\begin{array}{l}\text { Deviation between } \\
\text { PEMS and CVS }\end{array}$ & $\begin{array}{l}\text { Deviation } \\
\text { requirement }\end{array}$ & Pass/Fail \\
\hline $\mathrm{NOx}$ & $-3.75 \&$ & $\leqslant \pm 15$ & Pass \\
\hline $\mathrm{CO}$ & $10.7 \%$ & $\leqslant \pm 15 \%$ & Pass \\
\hline $\mathrm{CO} 2$ & $-1.2 \%$ & $\leqslant \pm 10 \%$ & Pass \\
\hline $\mathrm{PN}$ & $-22.7 \%$ & $\leqslant \pm 50 \%$ & Pass \\
\hline
\end{tabular}

It can be seen from Table 4 that the deviations measured by PEMs and CVS were within the allowable error range of regulation, indicating good status of PEMS equipment. In order to reduce the impact of connecting difference on measurement, the installation of PEMS remained unchanged throughout the entire series of repetition tests.

The velocities during repetition tests are shown in Figure 4, it can be seen that the whole series of repetition tests perfectly reproduced the speed curve of the same RDE test that would minimize the impacts of public traffic on emission.

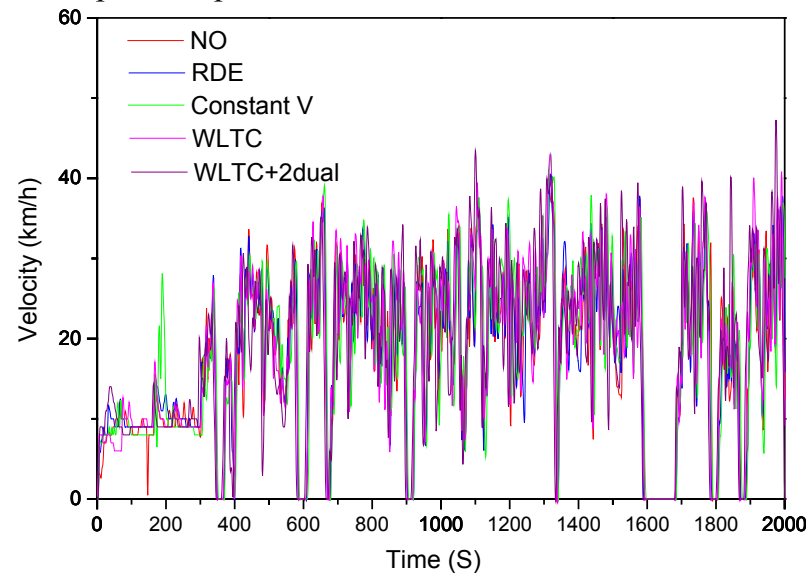

Fig. 4. Velocities during repetition tests.

In order to make effective statistics of all emission results, all window weights are adjusted to 1 , and the Primary tolerance of $\mathrm{CO} 2$ characteristic curve is set to $\pm 50 \%$, the data are evaluated forward. 
Figure 5 shows the NOx emission of urban trip during the series of repetition tests, where RAW indicating the original emission, MAW W/O cold indicating the moving average window method excluding cold start, MAW W cold indicating the moving average window method including cold start, pack4 indicating the method of the fourth RDE package of EU 6. In each group of emission statistics, five histograms from left to right represent the repetition tests at different preconditioning and soaking conditions, in sequence are no preconditioning, RDE test as preconditioning and soaking for 8 hours, constant speed preconditioning and soaking for 8 hours, WLTC test as preconditioning and soaking for 8 hours, and RDE test as preconditioning and soaking for 48 hours respectively.

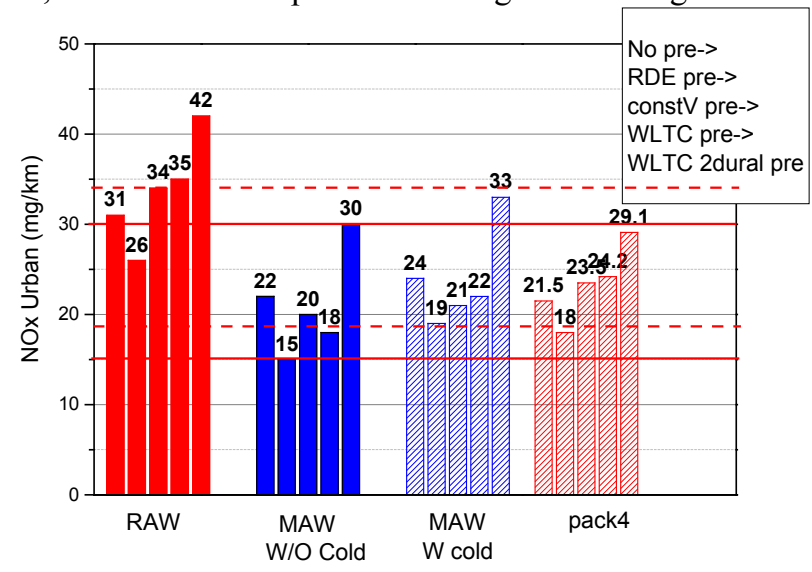

Fig. 5. NOx emission during urban trip.

It can be seen from Figure 5 that the emission obtained by MAW method is generally lower than the RAW emission, while the emission obtained by MAW method including cold start is slightly higher than that excluding cold start, with an increase ratio of about $5 \%$ $\sim 25 \%$. However, the emission obtained by the fourth RDE package does not have consistent High / low trend comparing to MAW method. In addition, no matter what kind of data processing method or preconditioning and soaking condition was used, differences existed in NOx emission during urban trip, but was not large enough to affect the pass/fail judgments, and the maximum difference in NOx emissions during urban trip obtained by the same calculation method under different preconditioning and soaking conditions is less than $15 \mathrm{mg} / \mathrm{km}$, that is even smaller than the allowable NOx deviation in PEMS validation test, which makes it difficult to fully attribute to the influence of preconditioning and soaking.

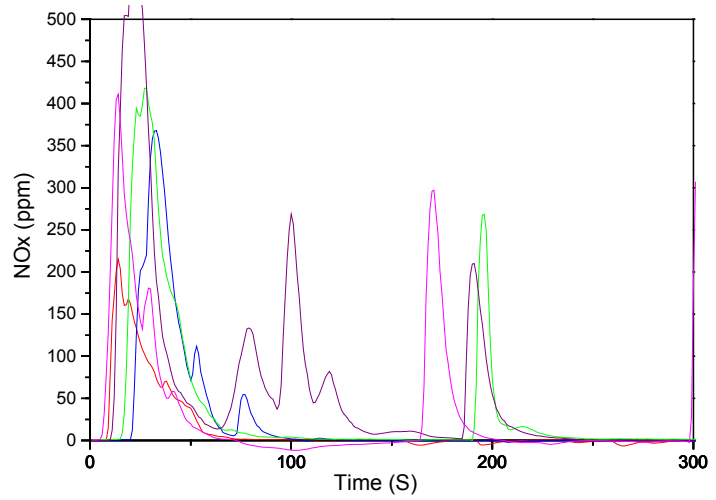

Fig. 6. NOx emission during cold start period. 
Figure 6 shows the NOx emission during cold start period, it is found that at a constant soaking time of 8 hours, no matter what preconditioning method is adopted, the NOx peak intensity and duration in the cold start period are similar, but when the soaking time is extended to 48 hours, the NOx peak intensity and duration in the cold start period increased. However, the factors affecting the emission cannot be simply attributed to the soaking time combining coolant temperature in Figure 7, it is found that the initial ambient temperature of the 48 hour soak test is relatively low, and the cooling water temperature is only about $45{ }^{\circ} \mathrm{C}$ after the vehicle runs for 5 minutes, which is also one of the factors causing the increase of NOx emission.

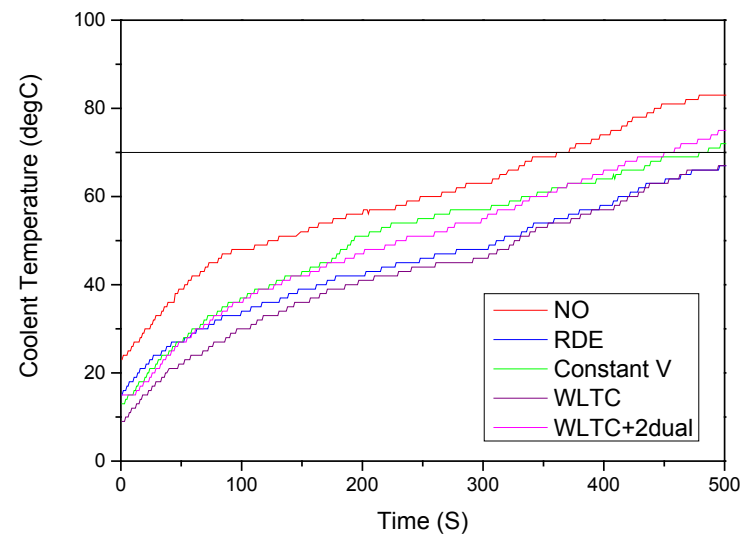

Fig. 7. Coolant temperature during repetition tests.

Figure 8 shows the PN emissions during urban trip of RDE test, from which it can be seen that the urban PN emissions obtained by MAW method including cold start are slightly higher than those obtained by MAW method excluding cold start, with an increase of about $10 \%-40 \%$. The PN emission obtained by the fourth RDE package of EU 6 is slightly higher than that obtained by MAW method, with an increase of about $2 \% \sim 60 \%$.

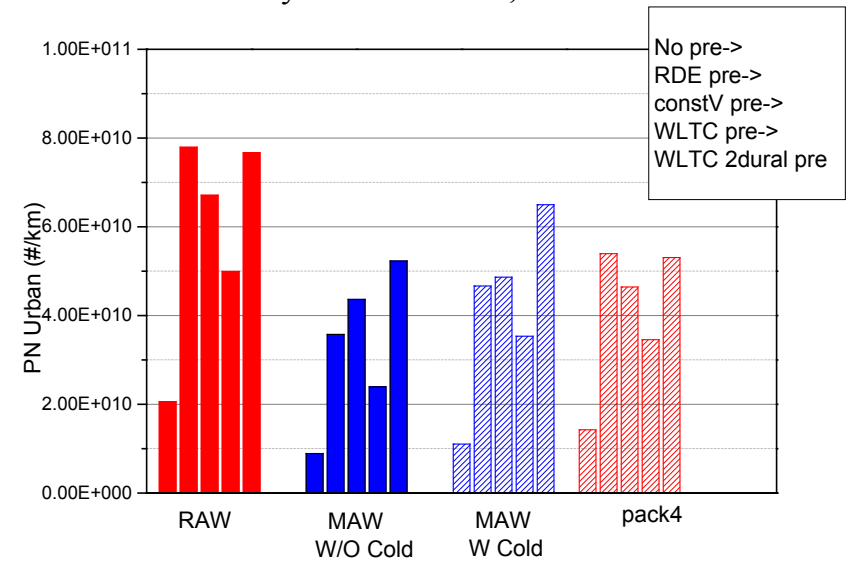

Fig. 8. PN emission during urban trip.

Figure 9 shows NOx emission during total RDE trip. From Figure 9, it can be seen that the NOx emission obtained by MAW method including cold start is slightly higher than that obtained by MAW method excluding cold start, but the proportion of increase is very small. However, the total NOx emission calculated by the fourth RDE package of EU 6 is lower than that obtained by MAW method excluding cold start, and the reduction ratio is about $13 \% \sim 22 \%$. 


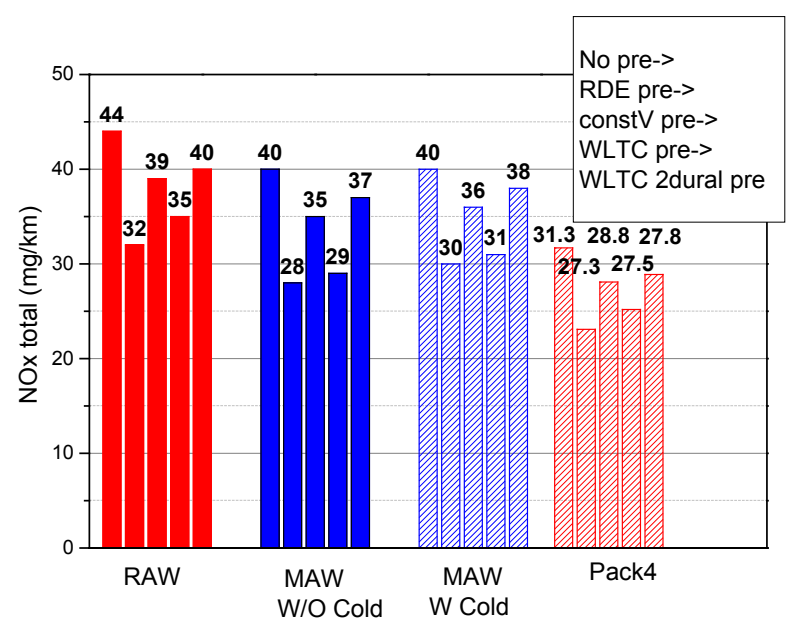

Fig. 9. NOx emission during total RDE trip.

Figure 10 shows the PN emission during total RDE trip. From Figure 10, it can be seen that the PN emissions obtained by the MAW method including cold start are slightly higher than those obtained by excluding cold start, but the increase proportion is very small, the maximum increase is only $7 \%$. However, the total PN emission calculated by the fourth RDE package of EU 6 is lower than that obtained by MAW method excluding cold start, and the reduction ratio is about $4 \% \sim 18 \%$.

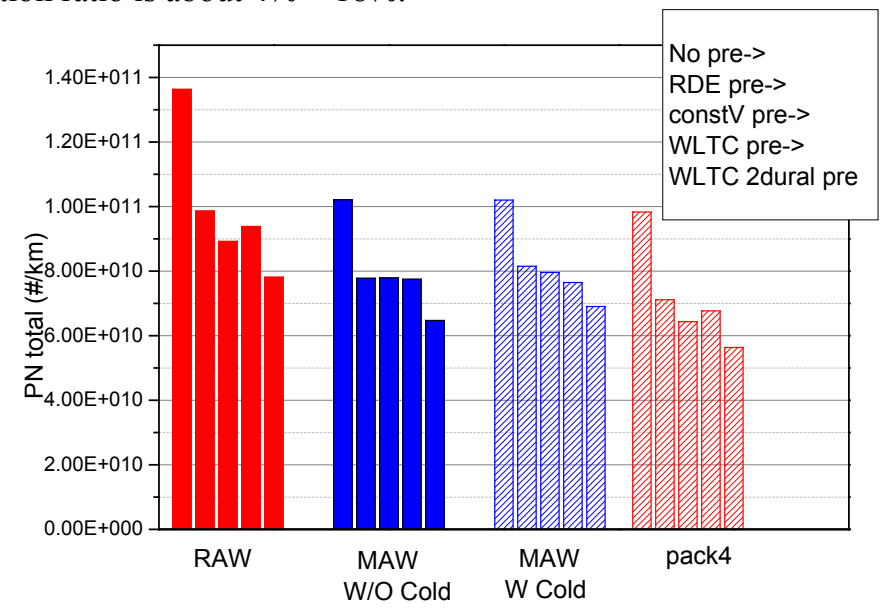

Fig. 10. PN emission during total RDE trip.

From Figure 5, Figure 8, Figure 9 and Figure 10 we can speculate that preconditioning and soaking methods had some impacts on emission of RDE tests, but these impacts are not large enough to affect the pass/fail judgment. In addition, when cold starts are taking account into the MAW method, generally higher emissions were obtained, but the fourth RDE package of EU 6 method does not have consistent High / low trend comparing to MAW method. In urban trips, the result calculated by the fourth RDE package of EU 6 generally increased comparing to MAW method. For the vehicles studied, the $\mathrm{CO} 2$ emission of RDE is much higher than that of WLTC, which is about 1.3 times. Under the data processing rules of the fourth RDE package of EU 6, the value of RF is only about 0.77 , that is to say, the final result is only about $77 \%$ of the original raw emission. One of 
the necessary conditions for the reasonable calculation results of package 4 is that the RDE and WLTC tests are carried out in full accordance with the regulations. All test parameters must be repeatedly confirmed. Any negligence will have a huge impact on the test results. The competent authority is also required to check the application information of the enterprise in detail, especially the items related to the emission strength (such as sliding resistance), and carry out test verification if necessary.

Generally speaking, the repeatability of these series of tests is acceptable. From the results, it is reasonable and feasible to directly use the third package of the EU RDE regulation to add cold start into statistics, and to carry out the corresponding requirements for the preconditioning and soaking. However, the data processing method of the fourth package not only changes the regulations basically, but also increases the requirements for the further supervision and verification.

\subsection{Data evaluation method}

The previous series of tests mainly focused on the preconditioning and soaking influence, even though different data evaluation method was used, but the overall test data is not enough, and the impact of data evaluation method is not clear. To avoid the statistical differences that may be caused by a single vehicle type, 27 additional vehicle types were studied, mainly focused on data evaluation method difference.

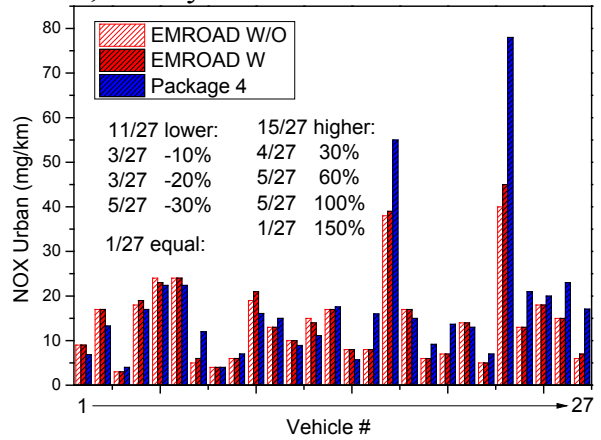

Fig. 11. NOx emission during urban trip with different data evaluating methods.

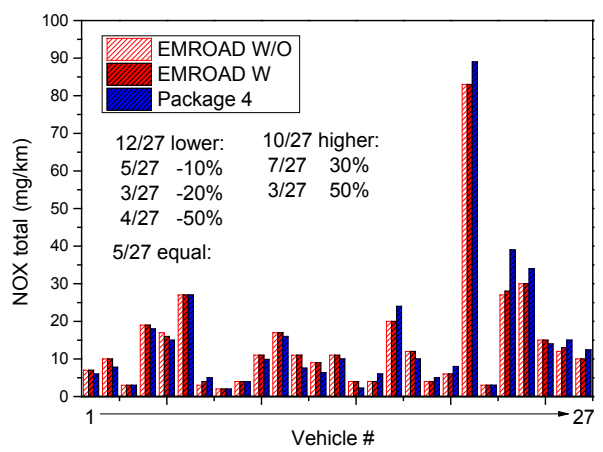

Fig. 13. NOx emission during total RDE trip with different data evaluating methods.

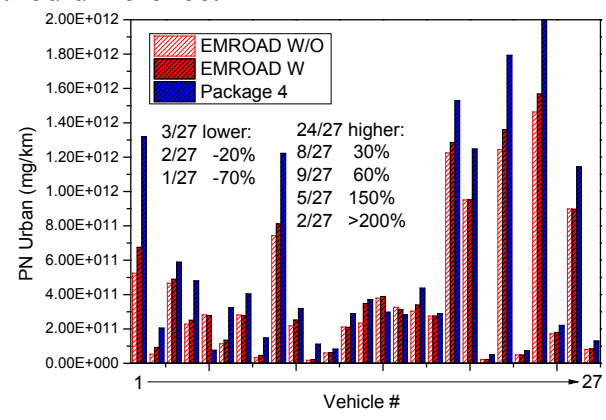

Fig. 12. PN emission during urban trip with different data evaluating methods.

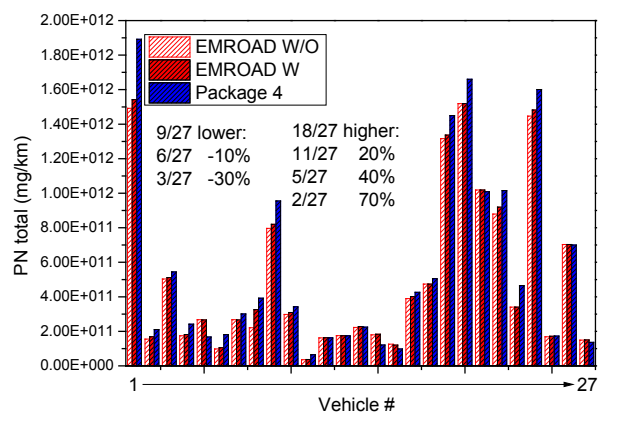

Fig. 14. PN emission during total RDE trip with different data evaluating methods.

Figure 11-14 shows the NOx and PN emissions during urban trip and total trip under different data evaluation methods, it can be speculated that if $\mathrm{CN} 6$ directly adopt the third package of the EU RDE regulation to add cold start into statistics, and to carry out the 
corresponding requirements for the preconditioning and soaking, the emissions during urban trip and total trip would slightly increase. However, if the data evaluation method of the fourth package is adopted, no consistent increase / decrease performance on NOx emissions in both urban and head office areas were observed. Nearly half of the NOx emissions decreased, with a maximum reduction range of $50 \%$, and the other half increase, with a maximum increase range of $150 \%$. There is no consistent increase / decrease performance on PN emission either. Nearly $1 / 3$ types decreased, with a maximum reduction range of $30 \%$, and nearly 2 / 3 types increased, with a maximum increase range of $200 \%$. Compared with MAW method, the calculation method of the fourth package had no stable consistency when dealing with cold start.

\section{Conclusion}

For the purpose of modifying the following RDE requirements of China 6 regulation, RDE tests on public road and repetition tests on Chassis dynamometer were carried out, and the relevant cold start requirements and new data evaluation method in EU 6 regulation were compared and discussed, the following results can be speculated:

1) Cold start is a very important stage of pollutant formation, and its emissions account for a considerable proportion, under some conditions, NOx emissions during cold start period can account for $12 \%$ of the total NOx emissions, and PN emissions can account for $11 \%$ of the total PN emissions. Cold starts contribute significantly to the air pollution in cities and should therefore be regulated appropriately;

2) The MAW has a risk that the data during cold start stage are contained in less data subsets if the data is calculated backward than forward, therefore, it is suggested that the revision of $\mathrm{CN} 6$ should refer to the revision principle of the EU standard by forcing the data processing direction forward;

3) The requirements of preconditioning and soaking in the third package of EU regulation is very general, which actually takes into account the diversity of actual use of vehicles, and no matter what kind of preconditioning and soaking condition was used, the differences in NOx and PN emission was not large enough to affect the pass/fail judgments;

4) Comparing with MAW method, the calculation method of the fourth package had no stable consistency when dealing with cold start.

\section{References}

1. Limits and measurement methods for emissions from light-duty vehicles (CHINA 6) (2016). http://kjs.mep.gov.cn/jbhbz/bzwb/dqhjbh/dqydywrwpfbz/201612/W020171207355626 647621.pdf

2. Commission Regulation (EU) 2016/427 of 10 March 2016 amending Regulation (EC) No 692/2008 as regards emissions from light passenger and commercial vehicles (Euro $6)$.

https://eur-lex.europa.eu/legal-content/EN/TXT/?qid=1587690463856\&uri=CELEX:3 2016R0427

3. Commission Regulation (EU) 2016/646 of 20 April 2016 amending Regulation (EC) No 692/2008 as regards emissions from light passenger and commercial vehicles (Euro $6)$. 
https://eur-lex.europa.eu/legal-content/EN/TXT/?qid=1587690603797\&uri=CELEX:3 2016R0646

4. Commission Regulation (EU) 2017/1154 of 7 June 2017 amending Regulation (EU) 2017/1151 supplementing Regulation (EC) No 715/2007 of the European Parliament and of the Council on type-approval of motor vehicles with respect to emissions from light passenger and commercial vehicles (Euro 5 and Euro 6) and on access to vehicle repair and maintenance information, amending Directive 2007/46/EC of the European Parliament and of the Council, Commission Regulation (EC) No 692/2008 and Commission Regulation (EU) No 1230/2012 and repealing Regulation (EC) No 692/2008 and Directive 2007/46/EC of the European Parliament and of the Council as regards real-driving emissions from light passenger and commercial vehicles (Euro 6). https://eur-lex.europa.eu/legal-content/EN/TXT/?qid=1587690691481\&uri=CELEX:3 2017R1154

5. Commission Regulation (EU) 2018/1832 of 5 November 2018 amending Directive 2007/46/EC of the European Parliament and of the Council, Commission Regulation (EC) No 692/2008 and Commission Regulation (EU) 2017/1151 for the purpose of improving the emission type approval tests and procedures for light passenger and commercial vehicles, including those for in-service conformity and real-driving emissions and introducing devices for monitoring the consumption of fuel and electric energy.

https://eur-lex.europa.eu/legal-content/EN/TXT/?qid=1587690771388\&uri=CELEX:3 2018R1832 